\title{
Analysis of the impact of using catalytic additives to fuel on exhaust emissions from a Diesel engine
}

\author{
Marcin Tkaczyk ${ }^{1 *}$, Konrad Krakowian ${ }^{1}$, Radosław Włostowski ${ }^{1}$, Zbigniew Sroka ${ }^{1}$ \\ 1 Wrocław University of Science and Technology; www.pwr.edu.pl \\ * Correspondence: marcin.tkaczyk@pwr.edu.pl Tel.: (+48 608249 824) (PL)
}

\begin{abstract}
The results from laboratory tests and field tests, available in the open literature for over ten years, despite the announcement of high efficiency translating into increased energy efficiency and such significant ecological advantages, have not so far resulted in widespread use of fuel performance catalysts (FPC) on a global scale. Wishing to explain why the above situation occurred and to verify the operation of catalytic additives for fuels; this article presents the results of research on the effect of using catalytic additives for fuel in a brand new diesel engine. The article contains an analysis of the results of exhaust gas emission tests from the Doosan MD196TI engine. During the tests, the engine was fueled with a typical diesel fuel and the same fuel with the a catalyst additive. The catalyst was added to the liquid fuel in the form of a commercially available product distributed by ProOne company under the name FMAX. The research was carried out in the form of a test, much more developed than the approval test on a stationary braking station in accordance with the requirements of ISO 8178. The article is concluded with a comparative analysis of exhaust gas emission results illustrating the effects of a catalyst in the form of reduction of solid particles, carbon monoxide, hydrocarbons and a slight increase in nitrogen oxide emissions. In addition, the effect of the catalyst depends on the product of thermal (brake) efficiency of the engine and the calorific value $(\mathrm{CV})$ of the fuel used.
\end{abstract}

Keywords: combustion engines; thermal efficiency; fuel performance catalysts.

\section{Introduction}

Compression ignition engines, also known as diesel engines, are still widely used in heavy duty road transport, all kinds of off-road solutions such as working machines, farm tractors, small power generation systems, heavy duty mining equipment or energy generators in maritime and inland shipping. On inland vessels, internal combustion engines are utilized for the main and the auxiliary propulsion [1,2]. As a result of the combustion process of hydrocarbon fuels, these engines produce exhaust gases containing: particulate matter (PM), various forms of hydrocarbons (UHCs), nitrogen oxides (NOx) as well as carbon monoxides (CO) and carbon dioxides (CO2) [1].

The main factor determining the possibility of utilizing a selected internal combustion engine for one of the above applications is the compliance with the relevant regulations. In the European Union, all applications of internal combustion engines for off-road applications, including inland navigation, are subject to the Regulations of the European Parliament and of the Council (EU) which EU member states are obliged to follow. (quote from the Regulation of the European Parliament and of the Council (EU) directive 2016).

The dynamically changing legal situation regarding the quality of gases emitted from combustion engines of the OFF-ROAD type, in the year 2019 led to the situation when on the market there was no supply of $130 \leq \mathrm{P}<300[\mathrm{~kW}]$ engines used for inland navigation. The Regulation of the European Parliament and of the Council (EU) of September 14, 2016 came into force on January 1, 2019, thus overnight changing the requirements concerning the emission standards from the Stage IIIa emissions level to the new Stage V emissions level. None of the companies in Poland, which deals in internal combustion engines for inland navigation was able to provide a brand new engine meeting the abovementioned requirements for a period of almost one year. That economic situation has led 
to the need for modification works on internal combustion engines aimed at achieving a new StageV emissions level by engines technologically prepared for lower emissions levels, namely Stage IIIIa.

One of the well-known ways to accelerate the combustion process in diesel engines and thus to make it more efficient and, consequently, to obtain a better quality exhaust gas is the addition of homogeneous combustion catalysts to diesel fuel [3]. Homogeneous combustion catalysts have several features which favor their use: they dissolve in diesel fuel uniformly, they do not get precipitated and agglomerated while being reloaded, stored and worn in the engine; they show high catalytic activity in supporting the combustion of hydrocarbons and it is already observed at the level of [ppm] in relation to the fuel, the properties of which do not significantly change or cause secondary pollution problems. [4]. Numerous metal ions have been found to promote the burning of hydrocarbons such as iron $[5,6,7,8]$, barium $[9,10]$, cerium $[11,12,13,14]$, manganese [15]; copper [16], platinum [17, 18, 19], and sodium [20].

Technologies for the production of metal-containing catalysts in a form of organometallic compounds or nano-particles have been developed [3, 21], claiming that they are best mixed with diesel. A statement was published about the advantage of iron-containing catalysts over others because, given the most important argument of their impact on the natural environment, the only products formed after combustion with such a catalyst are iron oxides, which are less toxic than other metal oxides [22, 23, 24]. The works of [25] illustrate the effectiveness of promoting the combustion process due to the utilization of iron picrate which is an organometallic compound made in controlled conditions from compounds containing iron and picric acid. The compound was called Fuel Performance Catalyst (FPC) and became a commercial product released on the market by Fuel Technology Pty Ltd. [26].

The fact of commercialization favored availability of the product, which encouraged further research into the question of the impact of the FPC catalysts on the performance of diesel engines. A number of laboratory and field tests was carried out, including a particularly significant research conducted since 2008 by a group of scientists from the Center for Energy at the University of Western Australia, which explained two issues: the effects of applying iron picrate as a diesel additive in diesel engines and the impact of the FPC on combustion and biodiesel emissions in a diesel engine. [27, 28, $29,30]$.

The most important achievements of the above authors include:

- systematization and confirmation of the previously generated data available in the open sources concerning the undeniable operation of the catalyst and the impact of the catalyst on the fuel efficiency of a diesel engine depending on the manufacturer, the engine size and application, fuel saving ranges from $1.1-7 \%$ [31, 32];

- recognition of the relation between fuel efficiency as a function of RPM and engine load. This fact is boiled down by the authors of the work to the statement that higher levels of emission reduction using the FPC are more visible in the engine working in its inefficient modes [27, 31, 32];

- documenting of the results of the measurement of fuel consumption during the operation of Caterpillar 793C trucks transporting the output from a mine in Western Australia and determining $2.5 \%$ reduction in the fuel consumption at $97 \%$ confidence level [3]; additionally, in the same field test, a reduction was observed in the emissions of PM solids by $39.5 \%$, carbon monoxide CO by $22.5 \%$ and UHC hydrocarbons by $15.3 \%$, and an increase in the emissions of NOx by $8.3 \%$.

- On the basis of experimental and theoretical analysis, possible mechanisms of the catalyst operation in the process of diesel fuel combustion were suggested $[29,30]$ under the influence of heat in a diesel engine, iron picrate gets decomposed (from 523K [29] and releases atoms of iron into the reaction zone, which promotes oxidation of fuel vapors in the air. This results in higher reaction rates and flame growth. Consequently, the heat transfer to the unburned fuel is increased by a higher flame temperature, which results in a higher burning rate and a shorter burning time. The findings are consistent with the literature based on observation, which was the grounds for arguing that a small number of iron atoms in a flame can promote ignition and hydrogen burning rate [33, 34], CO [35] and methane [36]. 
Apart from the abovementioned achievements, the authors of the study observing the decay of individual fuel droplets explained the effect of the FPC in the soot formation mechanism:

- it can be seen that the size of the primary soot and the catalyst-treated diesel aggregates was consistently smaller than the size of the untreated diesel soot and was further reduced by increasing the catalyst dose. That shows that FPC improves the efficiency of fuel combustion inside the engine, and therefore, the hydrocarbon fuel fragments burn more fully, leaving fewer soot precursors, creating the primary soot and aggregates, and, consequently, smaller particles are observed [27, 37];

- it was concluded that iron in the FPC embeds the catalysts in the soot and then activates the soot oxidation catalysis. It was proven that a small amount of transition metals or metal oxides can drastically increase the oxidation rate of the growing amount of soot [39].

The authors' achievements are crowned by an economic analysis in which they prove the profit which can be made by utilizing the FPC [31, 41].

The research, the findings of which are presented in this paper, was triggered by the need to transform an inland navigation engine that meets the Stage IIIa emissions standard. The authors of this article attempted to utilize an agent containing the FPC type catalyst distributed by the ProOne company under the name of Fuel Maximizer (FMAX). The composition of the FMAX agent is shown in Table 1.

Table 1. Ingredients FMAX

\begin{tabular}{|l|l|}
\hline Ingredients & Shares \\
\hline Naphtha Petroleum & $\begin{array}{l}60 \\
100 \%\end{array}$ \\
\hline Naphthalene & $3-7 \%$ \\
\hline $\begin{array}{l}\text { Organometallic } \\
\text { Compounds }\end{array}$ & $1-5 \%$ \\
\hline $1,2,4$-Trimethylbenzene & $0.1-1 \%$ \\
\hline
\end{tabular}

Based on the composition presented by ProOne in the form of the above table. The percentage of ferric chloride in FMAX is in the range of 1-5\%. The intention to use the abovementioned product was also encouraged by the desire to explain the problems associated with the promotion of the FPC products on the market, the unevenness of interest on various markets in the considered catalytic additives despite the long period of time which has passed since the publication of the technical and economic advantages of applying such means. This article presents the results of engine tests on a dynamometer bench built in accordance with ISO 81789. The results of a number of variables such as specific fuel consumption (sfc), particulate matter (PM) emissions, nitrogen oxides (NOx) as well as carbon monoxide and carbon dioxide are depicted as a function of load and rotational speed. The authors present the differences between the mentioned variables when supplying with a typical diesel fuel and a diesel fuel treated with FMAX. The scope of the tests goes far beyond the approval tests as the measurement was carried out at 32 points on the engine operation characteristics, thus providing the complete picture of the work. The innovation of the research presented in this paper is in the fact that the research was conducted on a brand-new engine featuring over twice as high thermal efficiency level as the efficiency levels presented in all the other publicly available publications. This article is concluded with proposals that reduce emissions of: particulate matter (PM) by $16.7 \%$, carbon monoxide (CO) by $9.8 \%$; total hydrocarbons (THC) $7.2 \%$ with an increase in nitrogen oxide (NOx) emissions by $1.1 \%$ on average in the full range of work for the FMAX treated fuel. The critical conclusion which can be drawn from the comparison of the research findings presented in this paper with the generally available research results is that there is a strong dependence of the catalytic additives application effects on the thermal efficiency of the engine 


\section{Effect of FPC additives on thermal efficiency improvements in diesel engines}

\subsection{Laboratory diesel engine tests}

The research methodology adopted for verifying the catalyst operation was based on engine tests containing the full range of engine operation. All tests have been prepared and carried out in full compliance with the ISO 8178 guidelines and relevant appendices. This solution allows a real assessment of the effects of the catalyst utilization without narrowing the scope of application of the engine (in this case a marine engine) to the applications declared by the manufacturer. The aspect of the extensive research which was carried out on the subject matter is an important result of this work, because the findings, their analysis and the conclusions show the impact of the catalyst use for the entire engine family and not only for a type or model of the engine limited to its applications on a specific market, industry or a facility. Such a research methodology explains its non-compliance with any particular test cycle defined by the ISO8178 standard. It should be emphasized that the research results presented in the work do not lose their properties for particular industries or applications because during analysis, it is possible to group the results from particular measurement points according to research cycles and, consequently, to direct the process of concluding. The only limitation to the scope of the tests is the use of an eddy current brake (ECB) for the testing, which makes the dynamic tests impossible. In accordance with the current EU law, the tests carried out in this way may apply to off-road engines. Precisely speaking, the scope of research and the work comply with COMMISSION DELEGATED REGULATION (EU) 2017/655 of 19 December 2016 supplementing Regulation (EU) 2016/1628 of the European Parliament and of the Council with regard to monitoring of gaseous pollutant emissions from in-service internal combustion engines installed in non-road mobile machinery.

The regulations regarding the test method, refer to the tests compliant with ISO 8178, carried out at the loading (dynamometer) station. Therefore, a brand new Doosan MD196TI internal combustion engine was installed on the stand, which in subsequent tests was powered by:

1. Typical fuel, pure diesel - untreated catalyst

2. Diesel with catalityc additives - fuel treated with a catalyst.

Both in the first test with the typical fuel and in the second test with the fuel modified by the operation of the catalyst, the engine was loaded in the full range of operation, i.e. at 39 points of the general characteristics. Table 2 illustrates the load points.

Table 2. Loads points

\begin{tabular}{|c|c|c|c|c|c|c|c|c|}
\hline & \multirow{2}{*}{ RPM [rpm] } & \multicolumn{7}{|c|}{ breake mean effective pressure BMEP [MPa] } \\
\hline & & 0.05 & 0.16 & 0.27 & 0.38 & 0.49 & 0.60 & 0.71 \\
\hline \multirow{6}{*}{ 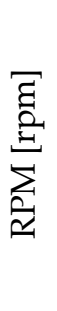 } & 1000 & 1 & 2 & 3 & 4 & 5 & 6 & \\
\hline & 1200 & 7 & 8 & 9 & 10 & 11 & 12 & 13 \\
\hline & 1400 & 14 & 15 & 16 & 17 & 18 & 19 & 20 \\
\hline & 1600 & 21 & 22 & 23 & 24 & 25 & 26 & 27 \\
\hline & 1800 & 28 & 29 & 30 & 31 & 32 & 33 & \\
\hline & 2000 & 34 & 35 & 36 & 37 & 38 & 39 & \\
\hline
\end{tabular}

The order of the measuring points was corresponds with the numbering presented in Table 2 . The measurement at each of the 39 points consisted in setting the combustion engine by the parameters of a given measuring point and then recording the measured values for 4 minutes.

The following values were recorded on the hard disk of a computer controlling the engine dynamometer:

1. Engine speed and engine torque

2. Fuel consumption

3. Measurement of gaseous and particulate emissions. 
Unfortunately, despite the repetition of the tests at points 1, 2, 7, 14, 21, 28, 34, the recorded results were incomplete. Therefore, further in the paper, those points are not taken into consideration. Thus, all calculations and analyses regard 32 points of the research. Measurement accuracy higher than expected in ISO 8178 standard was obtained in all points.

\section{2. Fuels}

Before the engine tests, the fuel tests were carried out:

a. Typical fuel - untreated catalyst

b. Fuel treated with a catalyst

Tests of the physical and chemical parameters included checking the following items in accordance with the following standards:

Table 3. The physical and chemical parameters

\begin{tabular}{|c|c|c|c|c|c|}
\hline Tested parameter & Test method & Unit & $\begin{array}{l}\text { Quality } \\
\text { reqiorements } \\
\text { of decree }\end{array}$ & $\begin{array}{l}\text { Typical } \\
\text { fuel }\end{array}$ & $\begin{array}{l}\text { Treated } \\
\text { with the } \\
\text { catalyst }\end{array}$ \\
\hline Density at $15^{\circ} \mathrm{C}$ & PN-EN ISO 12185: 2002, & $\mathrm{kg} / \mathrm{m}^{3}$ & $800.0-840.0$ & 810.5 & 810.5 \\
\hline Sulfur content & PN-EN ISO 20846: 2012 & $\mathrm{mg} / \mathrm{kg}$ & $\max .10 .0$ & 4.8 & 4.8 \\
\hline Water content & PN-EN ISO 12937: 2005 & $\mathrm{mg} / \mathrm{kg}$ & $\max .200$ & 50 & 30 \\
\hline $\begin{array}{l}\text { Cold filter } \\
\text { plugging point }\end{array}$ & PN-EN 116: 2015-09 & ${ }^{\circ} \mathrm{C}$ & $\max .-32$ & -37 & -38 \\
\hline Cloud point & PN-EN ISO 3015: 1997 & ${ }^{\circ} \mathrm{C}$ & $\max .-22$ & -38 & -39 \\
\hline Flashpoint & $\begin{array}{l}\text { PN-EN ISO 2719: 20016- } \\
08\end{array}$ & ${ }^{\circ} \mathrm{C}$ & powyżej 55.0 & 60.5 & 60 \\
\hline $\begin{array}{l}\text { Kinematic viscosity } \\
\text { at } 40^{\circ} \mathrm{C}\end{array}$ & PN-EN ISO 3104: 2004 & $\mathrm{~mm}^{2} / \mathrm{s}$ & $1.500-4.000$ & 1.708 & 1.647 \\
\hline $\begin{array}{l}\text { Policyclic aromatic } \\
\text { Hydrocarbons }\end{array}$ & $\begin{array}{l}\text { PN-EN ISO 12916: 2016- } \\
03\end{array}$ & $\%(\mathrm{~m} / \mathrm{m})$ & $\max .8 .0$ & 1.4 & 1.3 \\
\hline Cetane number & PN-EN ISO 5165: 2003 & - & $\min .51 .0$ & 53 & 53.1 \\
\hline Lubricity HFRR & $\begin{array}{l}\text { PN-EN ISO 12156-1: } \\
2016-04\end{array}$ & $\mu \mathrm{m}$ & $\max .460$ & 420 & 430 \\
\hline Oxidation stability & $\begin{array}{l}\text { PN-EN ISO 15751: } 2014 \text { - } \\
05\end{array}$ & $\mathrm{~h}$ & $\min .20 .0$ & $>30$ & $>30$ \\
\hline Oxidation stability & $\begin{array}{l}\text { PN-EN ISO 12205: } 2011+ \\
\text { Ap1: } 2013\end{array}$ & $\mathrm{~g} / \mathrm{m}^{3}$ & $\max .25$ & 4 & $<2$ \\
\hline $\begin{array}{l}\text { Copper strip } \\
\text { corrosion } \\
\left(\mathrm{Cu} / 3 \mathrm{~h} / 50^{\circ} \mathrm{C}\right) \\
\end{array}$ & PN-EN ISO 2160: 2004 & klasa 1 & klasa 1 & $1 \mathrm{a}$ & $1 \mathrm{a}$ \\
\hline FAME content & $\begin{array}{l}\text { PN-EN ISO 14078: 2014- } \\
06\end{array}$ & $\%(\mathrm{~V} / \mathrm{V})$ & $\max .7 .0$ & $<0.5$ & $<0.5$ \\
\hline $\begin{array}{l}\text { Total } \\
\text { contamination }\end{array}$ & $\begin{array}{l}\text { PN -EN ISO 12662: 2014- } \\
05\end{array}$ & $\mathrm{mg} / \mathrm{kg}$ & $\max .24 .0$ & $<12$ & $<12$ \\
\hline $\begin{array}{l}\text { Carbon residue on } \\
10 \% \text { distillation } \\
\text { residue }\end{array}$ & $\begin{array}{l}\text { PN-EN ISO 10370: 2014- } \\
12\end{array}$ & $\%(\mathrm{~m} / \mathrm{m})$ & $\max .0 .30$ & $<0.10$ & $<0.10$ \\
\hline
\end{tabular}




\begin{tabular}{|l|l|c|c|c|c|} 
Ash content & PN-EN ISO 6245: 2008 & $\%(\mathrm{~m} / \mathrm{m})$ & $\max .0 .010$ & $<0.001$ & $<0.001$ \\
\hline Cetane index & $\begin{array}{l}\text { PN-EN ISO 4264: } \\
\text { 201O/A1: 2013 }\end{array}$ & - & $\min .46 .0$ & 50.7 & 51 \\
\hline Manganese content & $\begin{array}{l}\text { PN-EN ISO 16576: 2014- } \\
12\end{array}$ & $\mathrm{mg} / 1$ & $\max .2 .0$ & $<0.5$ & $<0.5$ \\
\hline $\begin{array}{l}\text { Distillation - } \\
\text { recovered at } 180^{\circ} \mathrm{C}\end{array}$ & PN-EN ISO 3405: 2012 & $\%(\mathrm{~V} / \mathrm{V})$ & $\max .10 .0$ & 0.5 & 0.7 \\
\hline $\begin{array}{l}\text { Distillation - } \\
\text { recovered at 340 }{ }^{\circ} \mathrm{C}\end{array}$ & PN-EN ISO 3405: 2012 & $\%(\mathrm{~V} / \mathrm{V})$ & $\min .95$ & 98 & 98.5 \\
\hline
\end{tabular}

In all the items tested in accordance with separate standards, the diesel sample received the 'meets requirements' rating, both for the sample of a typical fuel, untreated with the catalyst, as well as for the sample of the same fuel, yet treated with the catalyst. The additive changed the fuel properties in twelve of the parameters tested. A significant change occurred in the "water content" parameter by changing the parameter value by $40 \%$ in the right direction, ie it bound $40 \%$ of the water contained in the fuel. The other twelve parameters were changed very little. Catalyst operation can be seen by observing the parameter "Distillation - recovered at 180" - the parameter value changes by $0.2 \%$, thereby increasing the amount of recovered fuel, which proves a faster reaction. The results of the conducted fuel tests are in line with the previously published findings which showed that the addition of the FPC catalyst has a slight effect on the fuel [42]. For the final recipient, this means that they can operate an engine supplying it with a fuel treated with an additive such as the tested one, and they will not experience any change in the durability of the fuel apparatus.

\section{3. Engine specification}

A type 4 cycle inline six-stroke combustion engine was used for the research. The cylinder diameter of $123 \mathrm{~mm}$ and the $155 \mathrm{~mm}$ piston stroke make up a displacement of $11,051 \mathrm{dm} 3$. The engine features the direct injection and the indirect water-cooled heat dissipation, both from the engine block and from the wet turbocharger as well as from the inter-cooler. According to the data declared by the manufacturer Doosan, the engine has: rating output (B.H.P) 235 [kW] achieved at 2,000 rpm thanks to achieving the mean effective pressure of $1.303 \mathrm{MPa}$.

The engine-loading element was the eddy current brake (ECB). The mode of operation is as follows: as a result of the generated electromotive force which was released from the control device by the engine test stand operator, the combustion engine connected to the brake with a Cardan shaft was loaded. The movable part of the brake unit was connected to the strain gauge thanks to which it was possible to determine the amount of force reflecting the size of the engine brake torque (Fig. 1). In addition, the brake was equipped with a shaft speed meter identical to the shaft speed of the tested engine.

The characteristics of the brake allowed forcing the maximum torque of Tmax $=2000 \mathrm{Nm}$ and could work at the highest speed of RPM $=5500 \mathrm{rpm}$, while the engine according to the manufacturer's data (quote) had a maximum torque of $\operatorname{Tmax}=1300 \mathrm{Nm}$, whereas the maximum rated speed is RPM = $2000 \mathrm{rpm}$. The dynamometer was located at Wroclaw University of Science and Technology.

\section{4. Gas analyzers specification}

The basic operation principle of the device:

The raw exhaust gas flow of approximately $3.5 \mathrm{dm} 3 / \mathrm{min}$ is sent to the device through a heated sampling line. In the heated filter, the particulates are removed from the raw exhaust gas and the flow is divided into two: one is directed to the FID and the other to the UV-RAS and NDIR analyzers and to the $\mathrm{O} 2$ sensor. The flow temperature through the FID is maintained at $191{ }^{\circ} \mathrm{C}$ up to the detector and then passes straight from the heated filter to the analyzer, where the THC and $\mathrm{CH} 4$ concentrations are measured in ppm. For that purpose, the heated filter is mounted close to the FID analyzer. The flow to UV-RAS and NDIR analyzers is precooled in ambient conditions after leaving the heated filter and 
directed to a two-stage refrigeration unit. After the first stage of the aggregate, the flow passes through a UV-RAS analyzer, in which separate NO and NO2 measurements are carried out. After the UV-RAS analyzer, the flow is again divided into two parts: each of them has a value of about $0.75 \mathrm{dm} 3 / \mathrm{min}$. One of those two parts of the flow passes through the other cooler, then $\mathrm{CO}$ and $\mathrm{CO} 2$ are measured after entering the NDIR analyzer and the oxygen content is determined by the $\mathrm{O} 2$ sensor. Both flows are limited by the passage in a calibrated orifice block. After passing through the pumps on the gas path from the UV-RAS and NDIR analyzers, there is a connection with the flow through the FID and the condensate flow from the cooling units at the outlet from the gas outflow of the entire PEMS analyzer module. The flow rate of up to $3.5 \mathrm{dm} 3 / \mathrm{min}$ are generated by the condensate pumps which remove the condensate from the cooling units (Fig. 1).

The FID, UV-RAS and NDIR and $\mathrm{O} 2$ analyzers measure the concentration of the exhaust components with pressure compensation in ppm or volume \%; the values can be visualized using the device's user interface (DUI) and processed by the software of the devices' manufacturer. The device used is manufactured by AVL, device type PM-PEMS iX with an accuracy of $<0.4 \%$ of reading.

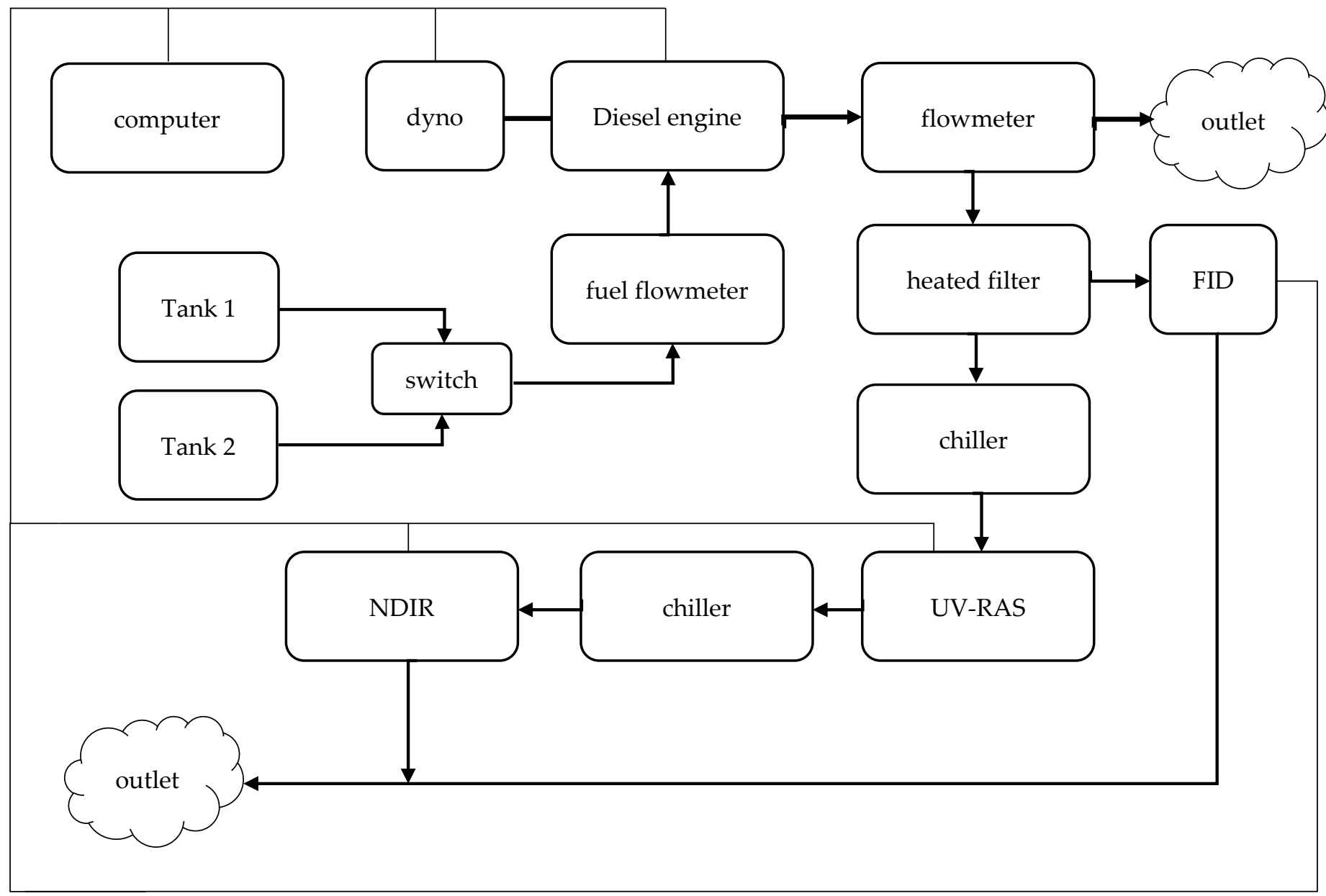

Figure 1. Functional diagram of the engine test bench with gas analyzers

For measuring particulate matter (PM), the AVL PM-PEMS device was used, the following functionality was used: Measurement of Soot, with a modified: Micro Soot Sensor, Dilution of the exhaust - constant, Dilution cell and sample line at $52^{\circ} \mathrm{C}, \mathrm{PM}$ filter at $42^{\circ} \mathrm{C}\left(32^{\circ} \mathrm{C}\right.$ to $\left.62^{\circ} \mathrm{C}\right)$. The accuracy of the AVL PM-PEMS used is $1 \%$, the repeatability in the range of $0.3 \%$ of full scale.

For measuring the flow in the exhaust system, an AVL flow meter mounted on a rusty diameter $129[\mathrm{~mm}]$ was used. Flow measurement accuracy $\pm 2.0 \%$ of reading or $\pm 0.5 \%$ of full scale, whichever is greater

\section{Analysis of the results}


Having carried out the tests, calculation of the obtained values was made so as to compute the final values.

1. The first stage consisted in calculating the actual value of the rotational speed and torque at each of the 32 measuring points.

For each of the measuring points, in order to calculate the average torque value, the following formula was used:

$$
\bar{T}=\sum_{t_{1}}^{t_{2}} \frac{T_{p}}{t_{2}-t_{1}}
$$

Where:

The $t_{1}$ and $t_{2}$ values were in each case determined by the person operating the software based on the formula. The guideline for determining the value was the provision of ISO 8178 requiring that the values recorded for a period of 1 minute be taken into account, i.e.:

$\mathrm{t}_{2}-\mathrm{t}_{1}=60[\mathrm{~s}]$

The same procedure was used for the rotational speed, i.e. its average value was calculated for each of the measuring points assuming the same values of $t_{1}$ and $t_{2}$.

$$
\overline{R P M}=\sum_{t_{1}}^{t_{2}} \frac{R P M_{p}}{t_{2}-t_{1}},
$$

Having obtained the average torque and engine speed values, it was possible to calculate, by means of formula [1], the average value of power for each of the 32 measuring points

$$
P_{A V R}=\frac{\bar{T} * \overline{R P M}}{9549,3},
$$

Based on the average value of the power output $[\mathrm{kW} / \mathrm{h}]$ and the average mass flow rate of fuel $\mathrm{mf}[\mathrm{g} / \mathrm{h}]$ for each of the points it was possible to calculate unit values. The unit values are the hourly values related to the power unit and in the case of fuel consumption, specific fuel consumption (sfc) is calculated:

$$
s f c=\frac{\dot{m}_{f}}{\dot{W}},
$$

For the specific case of the measurements, the following values were obtained: maximum $\mathrm{sfc}_{\mathrm{p}}=$ $266 \mathrm{~g} / \mathrm{kW} / \mathrm{h}$ and minimum $\mathrm{sfc}_{\mathrm{p}}=185 \mathrm{~g} / \mathrm{kW} / \mathrm{h}$, which provides average values for the considered 32 points:

$$
s f c_{A V R}=\sum_{t_{1}}^{t_{2}} \frac{s f c_{p}}{N_{p}}
$$

where:

$\mathrm{N}_{\mathrm{p}}$ - the number of measuring points

$s f c_{p}$ - specific fuel consumption at the operation point

Table 4. Average specific fuel consumption

\begin{tabular}{|c|c|}
\hline & $\begin{array}{c}\text { sfcAVR } \\
{[\mathrm{g} / \mathrm{kWh}]}\end{array}$ \\
\hline Pure diesel & 209 \\
\hline
\end{tabular}




\begin{tabular}{|c|c|}
$\begin{array}{c}\text { Diesel } \\
\text { with } \\
\text { catalyst } \\
\text { additive }\end{array}$ & 208 \\
\hline$\%$ & 0.9 \\
\hline
\end{tabular}

It should be emphasized that the total measurement error of sfc fuel consumption was $\pm 1 \%$, which means that it was greater than the result obtained, therefore the result cannot be considered. On the other hand, the result obtained is characterized by an error smaller than the maximum values of differences $7 \%$ obtained in the literature $[27,30,31,32]$, therefore, there is a discussion about the difference between BMEP and sfc in the test carried out and those documented in the literature:

- the scope of the research includes the tests conducted at BMEP from $0.16 \mathrm{MPa}$ to $0.71 \mathrm{MPa}$, while in the tests presented in the works by [43], they range from 0.13 MPa to 0.41 MPa of BMEP, which shows that a different generation of engines was applied;

- during the test, fuel consumption from sfc $=185[\mathrm{~g} / \mathrm{kW} / \mathrm{h}]$ to $\mathrm{sfc}=266 \mathrm{~g} / \mathrm{kW} / \mathrm{h}$ was recorded, while in the case of the data presented in [43] sfc ranges from $325 \mathrm{~g} / \mathrm{kW} / \mathrm{h}$ to $625 \mathrm{~g} / \mathrm{kW} / \mathrm{h}$. Comparison of the sfc values shows that, according to the formula, the product of thermal (brake) efficiency $\eta 0$ and the calorific value (CV) fuel is inversely proportional to sfc.

$$
s f c=\frac{1}{C V * \eta_{0}} \mathrm{a}=1,
$$

Taking into account the average values of the sfc for both of the considered cases, it can be calculated that the values used in the test by the researchers from Wrocław University of Science and Technology are over 2.14 times larger. Thus, assuming a similar calorific value of the fuel, the thermal efficiency of the tested engine is about twice as high as the efficiency of the engine tested by the employees of the University of Western Australia from Perth and published [43].

As far as the analysis of the test results including the analysis of fuel consumption at constant speeds and variable loads (Fig. 2) is concerned, a graph of the sfc value for the engine operating at a low speed of RPM $=1200[\mathrm{rpm}]$ is presented which illustrates:

1. An increase in the fuel efficiency which is greater at the less efficient work points, i.e.: the maximum values of fuel consumption depicted in the graph (Fig. 2.), for pure diesel at $\mathrm{sfc}=223.5$ $\mathrm{g} / \mathrm{kW} / \mathrm{h}$ are reduced by $2.6 \%$ for the diesel with the catalytic additives. The minimum fuel consumption presented in the same graph for pure diesel at $\mathrm{sfc}=195.2 \mathrm{~g} / \mathrm{kW} / \mathrm{h}$ is reduced by $0.5 \%$; this regularity coincides with the observations of the authors of [43].

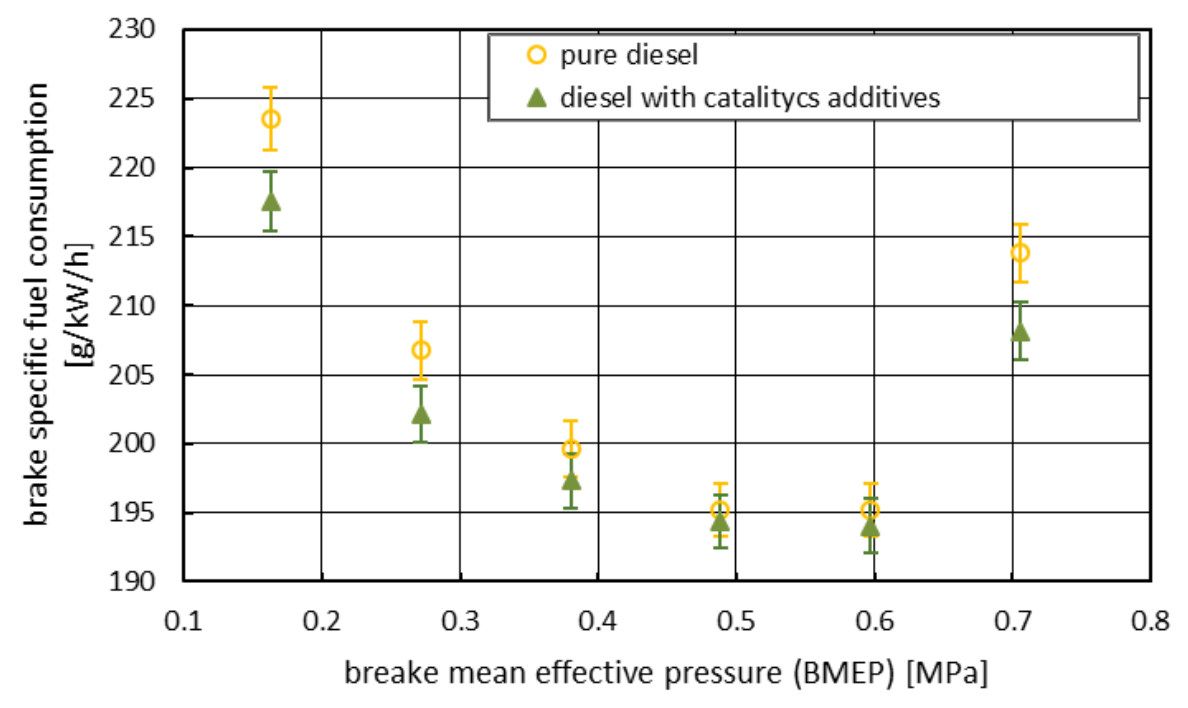

Figure 2. The brake-specific fuel consumption as a function of the engine load (BMEP). 
The data concerning the average power value, the mass emissions of exhaust gas components for each of the measuring points form the basis for calculating the unit emission values at those points.

In the case of emissions of exhaust gas components, we have:

Once the exhaust mass flow is available, the single species mass flow can be determined in accordance with EU legislation:

$$
\dot{m}_{x}=c_{x} * U_{x} * \dot{m}_{e x h}
$$

Where:

$\mathrm{C}$ - concentration (=ppm, molar fraction)

ISO 8178-1 defines Ux depending on the fuel type.

As a result of the abovementioned works, unit emission was obtained at points:

The purpose of the global assessment of the impact of the comparison of the abovementioned emissions was to average the emissions in the full range of work, based on the formula

$$
\overline{e_{x}}=\sum_{p_{1}}^{p_{n}} \frac{e_{p}}{N_{p}}
$$

Where:

$\mathrm{Np}$ - number of measuring point

ep - emissions of medium $x$ at a particular point of operation

The following was obtained:

Table 5. Compound emissions
\begin{tabular}{|c|r|r|r|r|}
\hline & NOx & PM & CO & THC \\
\hline $\begin{array}{c}\text { Pure } \\
\text { diesel }\end{array}$ & 7.32 & 0.18 & 1.29 & 0.89 \\
\hline $\begin{array}{c}\text { Diesel } \\
\text { with } \\
\text { catalist } \\
\text { additive }\end{array}$ & 7.41 & 0.15 & 1.16 & 0.82 \\
\hline$\%$ & -1.1 & 16.7 & 9.8 & 7.2 \\
\hline
\end{tabular}

Considering that NOx formation in diesel engines is caused by oxidation of atmospheric nitrogen and is largely dependent on the peak flame temperature [1, 2], thus the overall increase in NOx emissions (Table 5) measured during the test can be explained. As for the nature of the changes in the emissions (Fig. 3a) during load changes at one speed: uneven emissions increase is visible, but as for the values, fluctuations are low, independent of BMEP.

The most spectacular effect of using the catalytic additives is the reduction of PM emissions. The results presented in Table 5 show that the average reduction of PM emissions is $16.7 \%$. This observation is consistent with the evidence widely presented in the world literature which shows that a small amount of transition metals or metal oxides can drastically increase the oxidation rate of the accumulated soot [39]. The strong dependence of soot emission reduction on the engine operating conditions depicted in Figure $3 b$ shows that the increase in the emission reduction is specific to the areas featuring higher emissions.

On the whole, $\mathrm{CO}$ reduction is $9.8 \%$. The maximum reduction values fall into the area of the smallest and of the largest load. The range of average load values is manifested by similar values. Such results prove a greater reduction of $\mathrm{CO}$ in the areas with low excess of oxygen. In the case of the tested engine, those areas are observed at low speed values and at maximum rotational speed values (Fig. 3c).

The reduction of THC emissions (Fig. 3.d) reaches the value of $7.2 \%$ globally and varies depending on the engine operating conditions. As in the case of sfc, PM and CO, also in the case of 
$\mathrm{THC}$ there is an increase in the reduction in the regions of lower efficiency - especially at the low and at the maximum load.

Emission results for $2000 \mathrm{rpm}$ :
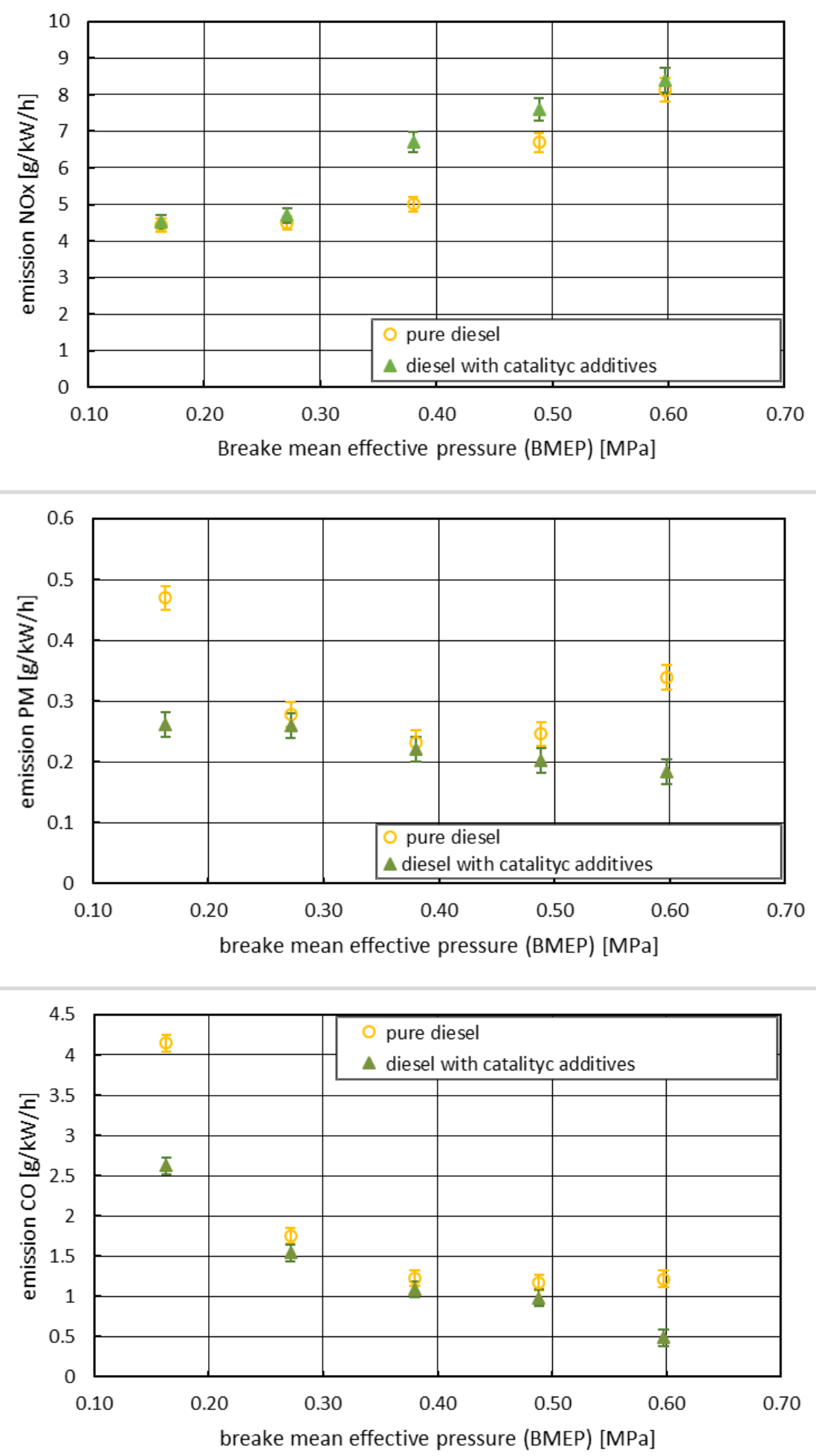


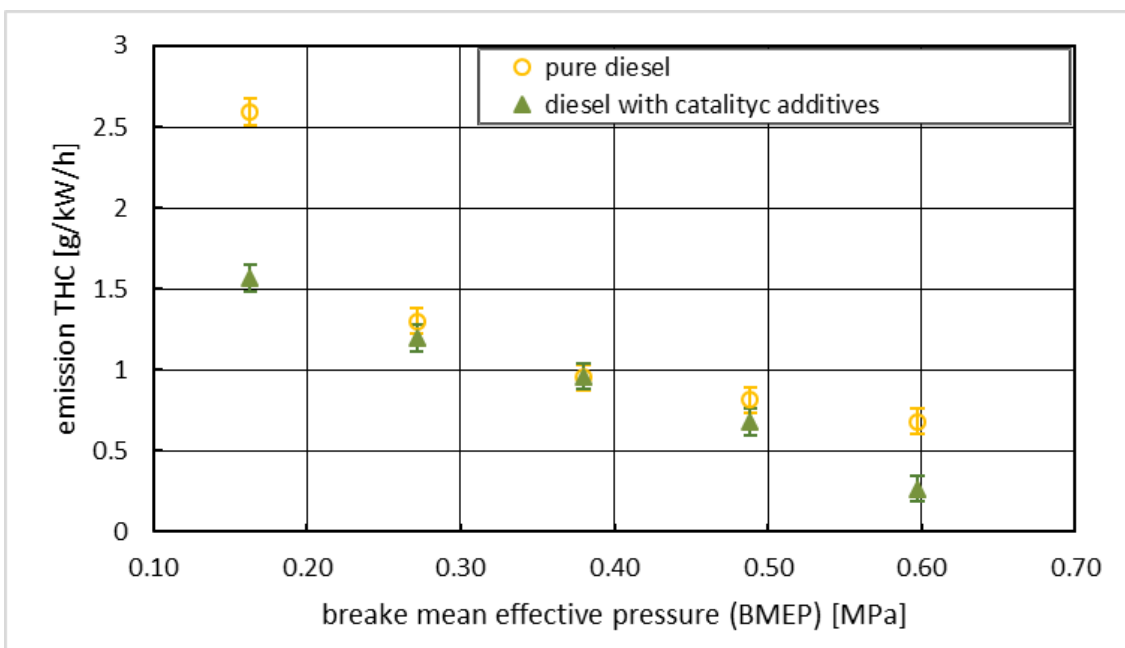

Figure 3. (a-d) NOx, PM, CO, THC emissions as a function of the engine load (BMEP).

\section{Conclusions}

The catalytic additive presented in this article does not significantly change the physicochemical properties of the fuel, which was confirmed by the presentation of a comparison of the results of the test on the fuel with the catalytic additive and pure diesel. The research showed that the additive does not have a negative impact on the fuel apparatus. The improvement in fuel efficiency was not confirmed in the diesel engine dynamometer tests because it was less than the measurement error. In addition, the measured performance improvement values were lower than those reported in the available literature. The authors note that the lower value of the efficiency improvement results from the application of an engine with generally much higher thermal efficiency compared to the previously published tests. A fundamental conclusion which can be drawn from the sentence above is that the impact of the catalyst on fuel efficiency ( $(\mathrm{fc})$ is strongly dependent on thermal efficiency of the engine and the lower the efficiency of the engine is, the higher fuel efficiency is observed. The conclusion was confirmed by the analysis of the engine operation range and boils down to the statement that the catalyst efficiency is higher in the lower efficiency ranges of the engine operation. Also, adding the catalyst to diesel may significantly reduce emissions of particulate matter (PM), unburned hydrocarbons and $\mathrm{CO}$ with a slight increase in NOx emissions.

Author Contributions: Conceptualization, M. T. and Z. S.; methodology, M. T.; software, K. K. and R. W; validation, M.T., K.K. and R.W.; formal analysis, M. T.; investigation, M. T.; resources, Z. S.; data curation, K. K.; writing - original draft preparation, M.T.; writing - review and editing, M.T.; visualization, M.T.; supervision, M.T.; project administration, M.T.; funding acquisition, Z.S. All authors have read and agreed to the published version of the manuscript.

Funding: This research received no external funding.

Acknowledgments: This research was supported by using resources GEO-3EM Energy, Ecology, Education co-financed by the European Regional Development Fund. Special thanks to the company Business Consulting AB for providing catalytic additives "ProOne Fuel Maximizer" for research.

Conflicts of Interest: The authors declare no conflict of interest.

\section{References}

1. Heywood, J.B. (1988) Internal Combustion Engine Fundamentals, McGraw-Hill, New York. 
2. Stone, R. (2005) Introduction to Internal Combustion Engines, SAE International, Warrendale.

3. Zhang, D. (2009) Homogeneous combustion catalysts for efficiency improvements and emission reduction in diesel engines. 7th Asia-Pacific Conference on Combustion.

4. Popova, O.V., Bashkatova, S.T., Vasil'eva, E.N., et al. (1995) Additives for increasing the completeness of combustion of diesel fuels. Chemistry and Technology of Fuels and Oils, 31, 88-94.

5. Parsons, J.B. and Germane, G.J. (1983) The effects of an iron based fuel catalyst upon diesel fleet operation. SAE paper: 831204.

6. Ritrievi, K.E., Longwell, J.P., and Sarofim, A.F. (1987) The effects of ferrocene addition on soot particle inception and growth in premixed ethylene flames. Combustion and Flame, 70, 17-31.

7. Zeller, H.W. and Westphal, T.E. (1992) Effectiveness of Iron-Based Fuel Additives for Diesel Soot Control, United State: Bureau of Mines, Washington, DC.

8. Zhu, M. (2012) A homogeneous combustion catalyst for fuel efficiency improvements in diesel engines fuelled with diesel and biodiesel. PhD. The University of Western Australia.

9. Howard, J.B. and Kausch, W.J. (1980) Soot control by fuel additive. Progress in Energy and Combustion Science, 6, 263-276.

10. Otto, K., Bartosiewicz, L., and Shelef, M. (1979) Effects of calcium, strontium, and barium as catalysts and sulphur scavengers in the steam gasification of coal chars. Fuel, 58, 565-572.

11. Blanchard, G., Colignon, C., Griard, C., et al. (2002) Passenger car series application of a new diesel particulate filter system using a new ceria-based fuel-borne catalyst: from the engine test bench to European vehicle certification. SAE paper: 2002-01-2781.

12. Jelles, S.J., Makkee, M., and Moulijn, J.A. (2001) Ultra low dosage of platinum and cerium fuel additives in diesel particulate control. Topics in Catalysis, 16-17, 269-273.

13. Jung, H.J., Kittelson, D.B., and Zachariah, M.R. (2005) The influence of a cerium additive on ultrafine diesel particle emissions and kinetics of oxidation. Combustion and Flame, 142, 276-288.

14. Wakefield, G., Wu, X.P., Gardener, M., et al. (2008) EnviroxTM fuelborne catalyst: developing and launching a nano-fuel additive. Technology Analysis and Strategic Management, 20, $127-136$.

15. Keskin, A., G"ur"u, M., and Altiparmak, D. (2008) Influence of tall oil biodiesel with $\mathrm{Mg}$ and Mo based fuel additives on diesel engine performance and emission. Biosource Technology, 99, 64346438.

16. Daly, D., Mckinnon, D., Martin, J., et al. (1993) A diesel particulate regeneration system using a copper fuel additive. SAE paper: 930131.

17. Fanick, E. and Valentiine, J. (2001) Emissions reduction performance of a bimetallic platinum/cerium fuel borne catalyst with several diesel particulate filters on different sulfur fuels. SAE paper: 2001-01-0904.

18. Jelles, S.J., Makkee, M., and Moulijn, J.A. (2001) Ultra low dosage of platinum and cerium fuel additives in diesel particulate control. Topics in Catalysis, 16-17, 269-273.

19. Kelso, D.T., Epperly,W., and Hart,M. (1990) Effects of platinum fuel additive on diesel emissions and efficiency. SAE paper: 901492.

20. Krutzsch, B. and Wenninger, G. (1992) Effect of sodium- and lithium-based fuel additives on the regeneration efficiency of diesel particulate filters. SAE paper: 922188.

21. Zhu, M., Ma, Y., and Zhang, D. (2011) An experimental study of the effect of a homogeneous combustion catalyst on fuel consumption and smoke emission in a diesel engine. Energy, 36, 60046009 .

22. Cho, S.H., Yoo, J.I., Turley, A., et al. (2009) Relationships between composition and pulmonary toxicity of prototype particles from coal combustion and pyrolysis. Proceedings of the Combustion Institute, 32, 2717-2725.

23. Fairbairn, E.A., Keller, A.A., and M"adler, L. (2011) Metal oxide nanomaterials in seawater: linking physicochemical characteristics with biological response in sea urchin development. Journal of Hazardous Materials, 192 (3), 1565-1571.

24. Falugi, C., Aluigi, M.G., and Chiantore, M.C. (2012) Toxicity of metal oxide nanoparticles in immune cells of the sea urchin. Marine Environmental Research, 76, 114-121. 
25. Parsons, J.B. and Germane, G.J. (1983) The effects of an iron based fuel catalyst upon diesel fleet operation. SAE paper: 831204.

26. Platt, R.A. (1999) Reduction in Greenhouse Gas Emissions by Application of a Combustion Catalyst, Fuel Technology Pty Ltd., Kewdale.

27. Zhang, D., Ma, Y., and Zhu, M. (2013) Nanostructure and oxidative properties of soot from a compression ignition engine: the effect of a homogeneous combustion catalyst. Proceedings of the Combustion Institute, 34, 1869-1876.

28. Zhu, M., Ma, Y., and Zhang, D. (2012a) Effect of a homogeneous combustion catalyst on combustion characteristics and fuel efficiency of biodiesel in a diesel engine. International Conference on Applied Energy, 5-8 July, Suzhou, pp. 960-967. This is an example of an ordered list.

29. Zhu, M., Ma, Y., and Zhang, D. (2012b) Effect of a homogeneous combustion catalyst on combustion characteristics of single droplets of diesel and biodiesel. Proceedings of the Combustion Institute, 34, 1537-1544

30. Zhu, M., Ma, Y., and Zhang, D. (2012d) A theoretical investigation into the effect of a homogeneous catalyst on combustion characteristics of single droplets of diesel and biodiesel. Chemeca 2012, 23-26 September, Wellington, pp. 543-553.

31. Zhu, M., Ma, Y., and Zhang, D. (2011) An experimental study of the effect of a homogeneous combustion catalyst on fuel consumption and smoke emission in a diesel engine. Energy, 36, 60046009 .

32. Zhu, M., Ma, Y., and Zhang, D. (2012c) Effect of a homogeneous combustion catalyst on the combustion characteristics and fuel efficiency in a diesel engine. Applied Energy, 91, 166-172.

33. Staude, S., Hecht, C., Wlokas, I., et al. (2009) Experimental and numerical investigation of FeCO5 to a laminar premixed hydrogen flame. Zeitschrift f "ur Physikalische Chemie, 223, 639-649.

34. Linteris, G.T. and Babushok, V.I. (2009) Promotion or inhibition of hydrogen-air ignition by iron containing compounds. Proceedings of the Combustion Institute, 32, 2535-2542.

35. Li, S. and Wei, X.L. (2011) Promotion of CO oxidization and inhibition of NO formation by gaseous iron species during hightemperature off-gas combustion. Energy \& Fuels, 25, 967-974.

36. Park, K., Bae, G.T., and Shin, K.S. (2002) The addition effect of FeCO5 on methane ignition. Bulletin of the Korean Chemical Society, 23, 175-176.

37. Ma, Y., Zhu, M., and Zhang, D. (2013) The effect of a homogeneous combustion catalyst on exhaust emissions from a single cylinder diesel engine. Applied Energy, 102, 556-562.

38. Kim, S.H., Fletcher, R.A., and Zachariah, M.R. (2005) Understanding the difference in oxidative properties between flame and diesel soot nanoparticles: the role of metals. Environmental Science\& Technology, 39, 4021-4026.

39. Ma, Y., Zhu, M., and Zhang, D. (2013) The effect of a homogeneous combustion catalyst on exhaust emissions from a single cylinder diesel engine. Applied Energy, 102, 556-562.

40. Popova, O.V., Bashkatova, S.T., Vasil'eva, E.N., et al. (1995) Additives for increasing the completeness of combustion of diesel fuels. Chemistry and Technology of Fuels and Oils, 31, 88-94.

41. Dongke Zhang, Mingming Zhu, YuMa, and Noel Millin. (2015) Homogeneous Combustion Catalysts for Efficiency Improvements and Emission Reduction in Diesel Engines. Handbook of Clean Energy Systems by John Wiley \& Sons, Ltd. DOI: 10.1002/9781118991978.hces016 